\title{
Publisher Correction: Impact of remotely generated eddies on plume dispersion at abyssal mining sites in the Pacific
}

\author{
Dmitry Aleynik $\mathbb{D}^{1}$, Mark E. Inall( $\mathbb{1}^{1,3}$, Andrew Dale $\mathbb{D}^{1}$ \& Annemiek Vink ${ }^{2}$ \\ Correction to: Scientific Reports https://doi.org/10.1038/s41598-017-16912-2, published online 05 December 2017 \\ In the original version of this Article, the ORCID ID and an additional affiliation for Mark E. Inall was omitted. \\ The correct affiliations are listed below:
}

SAMS, Scottish Association for Marine Science, Scottish Marine Institute, Oban, PA37 1QA, UK

Dmitry Aleynik, Mark E. Inall \& Andrew Dale

BGR, Bundesanstalt für Geowissenschaften und Rohstoffe, Stilleweg 2, 30655, Hannover, Germany Annemiek Vink

University of Edinburgh, School of Geosciences, Edinburgh, EH9 3FE, UK

Mark E. Inall

The original version of this Article also contained errors in the Materials and Methods section under subheading 'MIT-gcm model configuration'.

"A was developed to investigate mining pluhigh-resolution, non-hydrostatic ocean modelme dynamics in the region and to detect the location of enhanced mixing patches driven by the interaction of tidal and mean flow with bathymetry.".

now reads:

"A high-resolution, non-hydrostatic ocean model was developed to investigate mining plume dynamics in the region and to detect the location of enhanced mixing patches driven by the interaction of tidal and mean flow with bathymetry.".

The original version of this Article also contained errors in the Results section under subheading 'Modelling Plume Dynamics - the role of internal waves..

"The isolines 1 and $0.1 \mathrm{~cm}$ were found at respectively $\sim 5$ and $\sim 12 \mathrm{~km}$ away from the source and in the direction of dominant high eddy-induced flow (Fig. 5a), and substantially closer (1.5 and 6km respectively) in period II (Fig. 5b)."

now reads:

${ }^{1}$ SAMS, Scottish Association for Marine Science, Scottish Marine Institute, Oban, PA37 10A, UK. ${ }^{2} B G R$, Bundesanstalt für Geowissenschaften und Rohstoffe, Stilleweg 2, 30655, Hannover, Germany. ${ }^{3}$ University of Edinburgh, School of Geosciences, Edinburgh, EH9 3FE, UK. Mark E. Inall, Andrew Dale and Annemiek Vink contributed equally to this work. Correspondence and requests for materials should be addressed to D.A. (email: dmitry.aleynik@sams.ac.uk) 
"The isolines 1 and $0.1 \mathrm{~cm}$ were found maximum at respectively $\sim 5$ and $\sim 12 \mathrm{~km}$ away from the source and in the direction of dominant high eddy-induced flow (Fig. 5a), and substantially closer (1.5 and $6 \mathrm{~km}$ respectively) in period II (Fig. 5b)."

These errors have now been corrected in the HTML and PDF versions of the Article, and in the accompanying Supplemental Material.

(1) Open Access This article is licensed under a Creative Commons Attribution 4.0 International License, which permits use, sharing, adaptation, distribution and reproduction in any medium or format, as long as you give appropriate credit to the original author(s) and the source, provide a link to the Creative Commons license, and indicate if changes were made. The images or other third party material in this article are included in the article's Creative Commons license, unless indicated otherwise in a credit line to the material. If material is not included in the article's Creative Commons license and your intended use is not permitted by statutory regulation or exceeds the permitted use, you will need to obtain permission directly from the copyright holder. To view a copy of this license, visit http://creativecommons.org/licenses/by/4.0/.

(c) The Author(s) 2018 